\title{
Morphological Studies In Cryopreserved Buffalo Bull Spermatozoa
}

\author{
Fatma M Ibrahim, Hassan A Mansour, Faten M Labib, Hussein A Amer and \\ Rasha R Beheiry \\ Department of Theriogenology and Department of Histology and Cytology. Faculty of Veterinary \\ Medicine, Zagazig University.
} ABSTRACT

The present work was designed to study the ultrastructure of buffalo bull spermatozoa and to recognize the possible defects that may be occurred following the cryopreservation process. Fresh semen samples were collected from three buffalo-bulls from Mahallet Musa buffalo research station in Kafr El-shiekh Government for production of buffalo-bull sires. Straws of cryopreserved semen were obtained from Kafr El-Shiekh Center for frozen buffalo-bull semen. All these samples were prepared for examination by transmission electron microscope. The results reveal that the freshly collected spermatozoa from apparently healthy buffalo bull consist of: head and tail. The tail attached to the head axially and consists of neck, middle piece, principle piece and end piece. The head consists of the acrosome and the nucleus surrounded by the plasma membrane. The neck located between the head and middle piece and has fossa in which the centriole is located. The middle piece is characterized by the mitochondrial sheath that surrounds the flagellar core in $9+2$ axonemic arrangement and the nine outer dense fibers (ODF). The principle piece is the longest portion of the spermatozoon. It has flagellar core, dense fibers and fibrous sheath. The fibrous sheaths are made of two longitudinal columns, a dorsal and a ventral one, and connecting ribs. The end piece contains only the axial filament complex. The results revealed the effect of cryopreservation on ultrastructure of buffalo bull spermatozoa; disruption, undulation and damage of plasma membrane, detached and disintegration of acrosome, decondensation of chromatin of the nucleus, bent and swelling middle piece, breakage of the plasma membrane of middle piece and loss of some of the mitochondria, irregular shaped mitochondria, irregular arrangement and shape of dense fibers and distorded axonemes.

\section{INTRODUCTION}

There are 170 million buffaloes in the world, 97\% in Asia, 2\% in Africa mainly in Egypt, and $0.2 \%$ in Europe mainly in Italy (1). Artificial insemination has many advantages such as controlling of the genital disease among females, avoiding bull exhaustion and improving the genetic quality of the herd (2). Species differences in female tract anatomy, differences in sperm transport mechanisms, ability to time inseminations and deliver spermatozoa effectively are powerful determinants of fertility with cryopreserved spermatozoa (3). The successful cryopreservation of spermatozoa can be found in many fields, including agriculture, laboratory animal medicine, and human assisted reproduction, providing a cost-effective and efficient method to preserve genetic material for decades (4).

Artificial insemination using cryopreserved semen is common management tool of live stock producer; however, cryopreservation is detrimental to sperm fertility, killing about $50 \%$ of spermatozoa during the cryopreservation process and causes damage to other sperm cells (5).

The percentage of live spermatozoa determines the quality of the ejaculate. Semen with more than $30 \%$ initial dead spermatozoa may not be suitable for storage and freezing. 
Differential staining techniques have been used for determination of live and dead spermatozoa (6). Two techniques can be used for assessment of sperm viability: the optical eosin-nigrosin assay and the fluorescence live-dead assay (7).

Sperm abnormalities have traditionally been classified by location of the defect (head, mid piece, tail), or its site of origin: primary (testis), secondary (epididymis) and tertiary (accessory glands/post-ejaculation),(8).

The aim of the present work was to study the ultrastructure of the fresh buffalo bull spermatozoa as well as some of the sperm alterations during freezing processes which may interfere with fertility in buffalo.

\section{MATERIALS AND METHODS}

Source of the semen sample

\section{Fresh semen sample}

The fresh semen samples were obtained from three Buffalo-Bulls that were kept in Mahallt Musa buffalo research station related to animal research institute, agricultural research center. The selected Buffalo-Bulls were subjected to clinical examination and proved to be in good general condition, free from any general and genital diseases. Moreover, they were characterized by acceptable libido and good semen quality and quantity. Their ages were ranged around four years. They had an average body weight of 400-450 kg. They were housed in an open yard where $50 \%$ of the yard area was sheltered and the animals have free access of water.

\section{Semen Collection}

Semen samples were collected using the artificial vagina (AV). The semen collected with good hyagine conditions and immediately transferred to the laboratory.

\section{General evaluation of the semen samples}

Each ejaculate was subjected to macroscopic evaluation and divided into two parts; the first was used to conduct microscopic evaluation (9) while the second part was preserved in glutaraldehyde solution till the time of preparation for examination by electron microscope (10).

Macroscopic evaluation of the semen samples

The ejaculate volume was directly measured in the graduated tube. Physical characters of the ejaculate (the color, density, presence or absence of any admixtures as well as gross motility) were determined directly after collection.

Microscopic evaluation of the semen samples

\section{Sperm Motility}

The freshly collected semen samples were evaluated for both mass and individual motility (9) (tables 2\&3).

\section{Mass Motility}

Evaluation of mass motility reflects combined effect of concentration as well as the viability of sperm cells. It is determined by observing a thick drop of fresh semen under low power using an objective X10 and reduced light.

\section{Individual Motility}

The percentage of the progressive forward motility is only calculated. Circling, reverse, as well as stationary motility were ignored. The initial estimation of the percentage of progressively motile sperms was done in order to estimate the total progressively motile sperms per ejaculate. Individual motility was assessed using one drop of semen on a previously warmed slide diluted to a ratio of 1:3 with $2.9 \%$ Sodium citrate. The diluted semen is covered with a cover slip to provide a uniform film, restrict movement of the floating sperm cells and delay drying of the examined smear. The prepared slide was examined at high power using an objective 40X. 


\section{Sperm Cell Concentration}

Sperm cell concentration of each ejaculate was determined using Neubauerhemocytometer in manner similar to that used in making a red blood cell count (11). The diluents used is saline to which $0.01 \%$ mercuric chloride, $2 \%$ sodium hydroxide or few drops of formalin are added to suppress the motility of the sperm when examining fresh samples, otherwise saline alone will be sufficient. One drop of saturated watery solution of eosin or methylene blue was found to be useful for staining the sperm and making them more distinct and to be easily seen in the chamber. Semen was diluted by an extension rate of 1: 200. The killed sperms in 5 secondary (large) squares were counted in a diagonal direction. The number of the counted sperms was multiplied by 10,000 (12).

\section{Frozen Semen Sample}

Straws of frozen semen were obtained from international center for training on the animal welfare and embryo transfer in Sakha. Six mini straws were used for making three resin blocks .
Freezing was performed at -90 to $100^{\circ} \mathrm{C}$ for 12 minute. Total time of cooling was 5 hours. The first hour for gradual cooling, while the last 4 hours for equilibration. The straws were thawed and preserved in glutaraldehyde solution.

\section{For electron microscopy}

Samples were centrifuged at $3500 \mathrm{rpm}$ for 10 minutes and immediately fixed in $2 \%$ glutaraldehyde solution in $0.1 \mathrm{M}$ sodium phosphate buffer $\mathrm{pH} 7.4$ at $4^{\circ} \mathrm{C}$ for 3 hours and post fixed in $1 \%$ osmic acid. After dehydration in ethanol series, all specimens were embedded in Epon-Araldite. The selected blocks were sectioned using diamond knives into ultra-thin sections that were mounted on naked copper grids and stained with uranyl acetate and lead citrate. The sections were examined and photographed with TEM operating at $80 \mathrm{kv}$ (10).

The obtained specimens, blocks and sections of both fresh and frozen Buffalo-Bull semen samples, as well as the total number of fields captured, in addition to the different magnification power were represented in table 1.

Table 1. Series of steps performed for preparing the final sections examined by TEM for fresh and frozen Buffalo-Bull semen specimens

\begin{tabular}{|c|c|c|c|c|c|c|}
\hline \multirow[t]{2}{*}{ Criteria } & \multicolumn{3}{|c|}{ Fresh semen } & \multicolumn{3}{|c|}{ Frozen semen } \\
\hline & Initial & Repitition & Total & Initial & Repitition & Total \\
\hline Number of samples collected & 3 & & & 3 & & \\
\hline Number of ejected samples & 1 & & & 1 & & \\
\hline $\begin{array}{l}\text { Number of samples those } \\
\text { exactly examined }\end{array}$ & 2 & & & 2 & & \\
\hline $\begin{array}{l}\text { Number of blocks made from } \\
\text { each sample }\end{array}$ & 4 & & & 4 & & \\
\hline Number of rejected blocks & 2 & & & 2 & & \\
\hline $\begin{array}{l}\text { Number of blocks those exactly } \\
\text { sectioned }\end{array}$ & 2 & & & 2 & & \\
\hline $\begin{array}{l}\text { Number of thin sections made } \\
\text { from each block }\end{array}$ & 3 & $3 \mathrm{X} 2$ & 6 & 3 & $3 \times 2$ & 6 \\
\hline $\begin{array}{l}\text { Number of fields captured from } \\
\text { each section }\end{array}$ & 8 & $8 \times 6$ & 48 & 8 & $8 \times 6$ & 48 \\
\hline Magnification power used & \multicolumn{6}{|c|}{$\begin{array}{c}\mathrm{X} 1000, \mathrm{X} 4000, \mathrm{X} 6000, \mathrm{X} 8000, \mathrm{X} 10000, \mathrm{X} 15000, \mathrm{X} 20000, \mathrm{X} 30000 \text { and } \\
\text { X40000. }\end{array}$} \\
\hline
\end{tabular}


Microscopic evaluation of the semen samples

\section{RESULTS}

Sperm Motility

Mass Motility

The mass motility was scored from 0 to 4 according to the intensity of moving whirls (table, 2). Ejaculates less than 3 were rejected.

Table 2. Descriptive and numerical scales for evaluation of the microscopic wave patterns of bull semen

\begin{tabular}{ccl}
\hline $\begin{array}{c}\text { Descriptive } \\
\text { Scale }\end{array}$ & Numerical Scale & \multicolumn{1}{c}{ Appearance } \\
\hline Very poor & 0 & Waves not present, sperms immotile \\
Poor & 1 & Waves not present, sperm cells motile \\
Fair & 2 & Barely distinguishable waves \\
Good & 3 & Waves apparent, moderate motion \\
Very good & 4 & Dark, distinct waves in rapid motion. \\
\hline
\end{tabular}

Individual Motility

The results were recorded according to the descriptive and numerical values presented in table 3. At least $80 \%$ of motile cells should exhibit the progressive type of motility.

Table 3. Descriptive and numerical scales for evaluation of the microscopic individual motility of sperm cells

\begin{tabular}{ccc}
\hline$\%$ of Motile Cells & Descriptive value & Numerical value \\
\hline $80-100 \%$ & Very good & 5 \\
$60-80 \%$ & Good & 4 \\
$40-60 \%$ & Fair & 3 \\
$20-40 \%$ & Poor & 2 \\
$0-20 \%$ & Very Poor & 1 \\
\hline
\end{tabular}

Ultrastructures of Spermatozoa of freshly The acrosome

collected semen of buffalo bull:

The examination of prepared semen samples under TEM revealed that, mature spermatozoa are enclosed inside plasmalemma and consist of: head and tail. The tail is the longest part of the sperm. The tail attached to the head axially and consists of neck, middle piece, principle piece and end piece (fig. 1).

Head

The sperm head consists of the acrosome (head cap) and the nucleus surrounded by the plasma membrane (figs. 2 and 3).
The acrosome forms a cap-like structure covering the first two thirds of the sperm head. It consists of an inner and an outer acrosomal membrane(fig. 2). It is cut into three different segments: (a) the anterior margin that is the apical segment (showing acrosomal ridge;there was small enlargement toward ventral surface so it take the shape of tongue like protrusion), (b) the segment back over the anterior half that is called main segment and (c) the caudal portion of the cap that is the equatorial segment (fig. 4). 
The nucleus

The nucleus contains the condensed chromatin. The shape of the nucleus is speciesspecific and usually flattened dorsoventrally. There is a small area of uncondensed chromatin (fig.4) where transcription, translation and protein-biosynthesis are still possible.

The implantation groove

Groove is present at the caudal end of nucleus, it is species specific and it is limited by nuclear envelope. (fig. 4)

Neck

It is short and narrow structure between the head and middle piece so it called (connecting piece). It has fossa in which the centriole is located (the proximal centriole whereas the distal centriole is absent in mature spermatozoa) and nine peripheral, longitudinally oriented dense fibers continuous with the outer dense fibers of the middle piece (fig. 1).

Middle piece

The middle piece is characterized by the mitochondrial sheath (figs. 2,5,6) that surrounds the axonemal complex and the nine ODF. The axonemal complex consists of a central pair of two single microtubules (figs.5,6) that is surrounded by a cylindrical bundle of uniformly arranged nine double microtubules. They are surrounded by longitudinally oriented, tapered outer fibers that are connected to the fibers of the connecting piece called (ODF). The nine ODF (figs. 5,6) are peripherally arranged around the axoneme in the proximal part of the flagellum. They have a dense, inhomogeneous structure and a rounded outline that tapers to the narrower edge and is directed to the doublets of the axoneme.

The ODF differ among them in shape in cross sectional area (fig.6). All of the ODF are thickest in the proximal part of the middle piece and progressively diminish in diameter from base to tip of tail.

The mitochondria are arranged end to end in helices around the contractile elements in longitudinal section (fig. 2), while it wraps laterally around the outer dense fiber in cross section (figs. 5, 6).

At the caudal end of the mitochondrial sheath is the annulus or Jensen's ring respectively ring centriole that marks the barrier between mid piece and principle piece(fig. 2).

\section{Principle piece}

The principle piece is the longest portion of the spermatozoon. The axial filament complex has a structure identical to that of middle piece and is surrounded by the outer fibers of the middle piece. It is enclosed by fibrous sheaths that are made of two longitudinal columns, a dorsal and a ventral one, and circumferentially oriented connecting ribs. One raw of radial spokes radiate inward toward the central pair of microtubules (fig. 7).

The thickness of the principle piece decreases toward the end piece so we find in this study principle piece with different diameter in cross section so we divide the principle piece into two level (a) level 1 at the upper third of principle piece and (b) level 2 at the lower third of principle piece.

\section{End piece}

The termination of the fibrous sheath marks the beginning of the end piece, which contains only the axial filament complex.

There are primary abnormalities as short head (Fig.8) and double tail (fig.7) beside the defects due to freezing.

Freezing induced defects in ultrastructure of buffalo bull spermatozoa as being detected by TEM:

Plasma membrane

Disruption and undulation of plasma membrane (fig. 9) ,absence of plasma membrane (figs. 8,10) and Destruction of plasma membrane (figs. 11,12).

Head

Acrosome

Ruptured plasma membrane and the outer acrosomal membrane, disintegration of acrosome and remnants of its content adhering to the nucleus (fig. 10) and detached acrosome (fig. 11), 
Nucleus

Decondensation of chromatin of the nucleus (figs.8,9,10,13).

Tail

The present study showing bent middle piece (figs. 8,14 ) in addition to swelling of middle piece (figs.10,15), breakage of the plasma membrane of middle piece and loss of some of the mitochondria, irregular shaped mitochondria, disordered mitochondria (figs.9,10), irregular arrangement and shape of dense fiber (fig. 12) and distorded axonemes (figs.8,9,11,13).

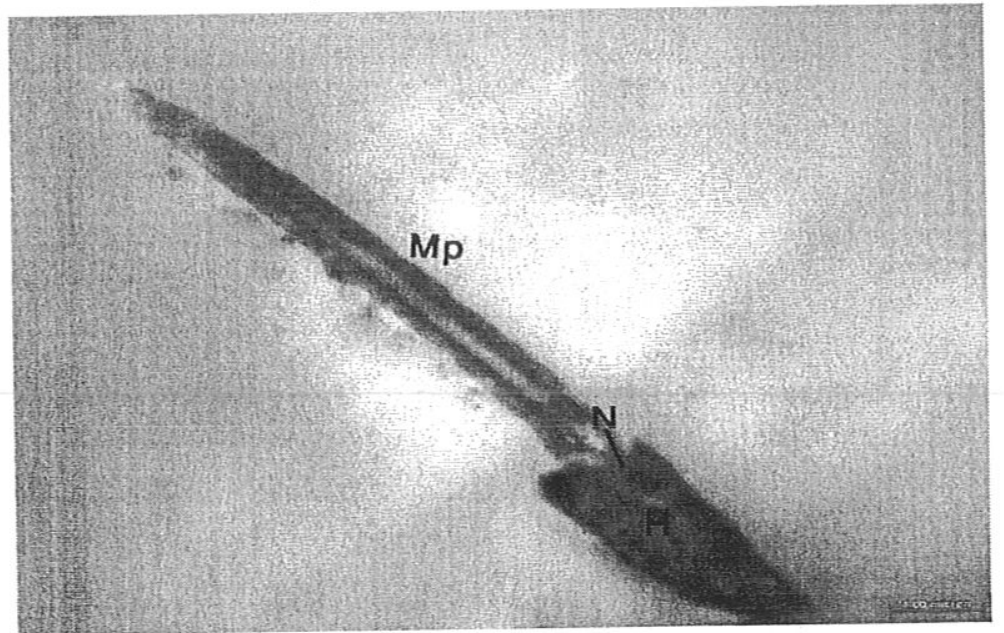

Fig. 1. Electron micrograph of normal semen of adult buffalo bull showing longitudinal section of spermatozoon, head $(H)$, neck $(N)$, middle piece $(M P)$ : X8000

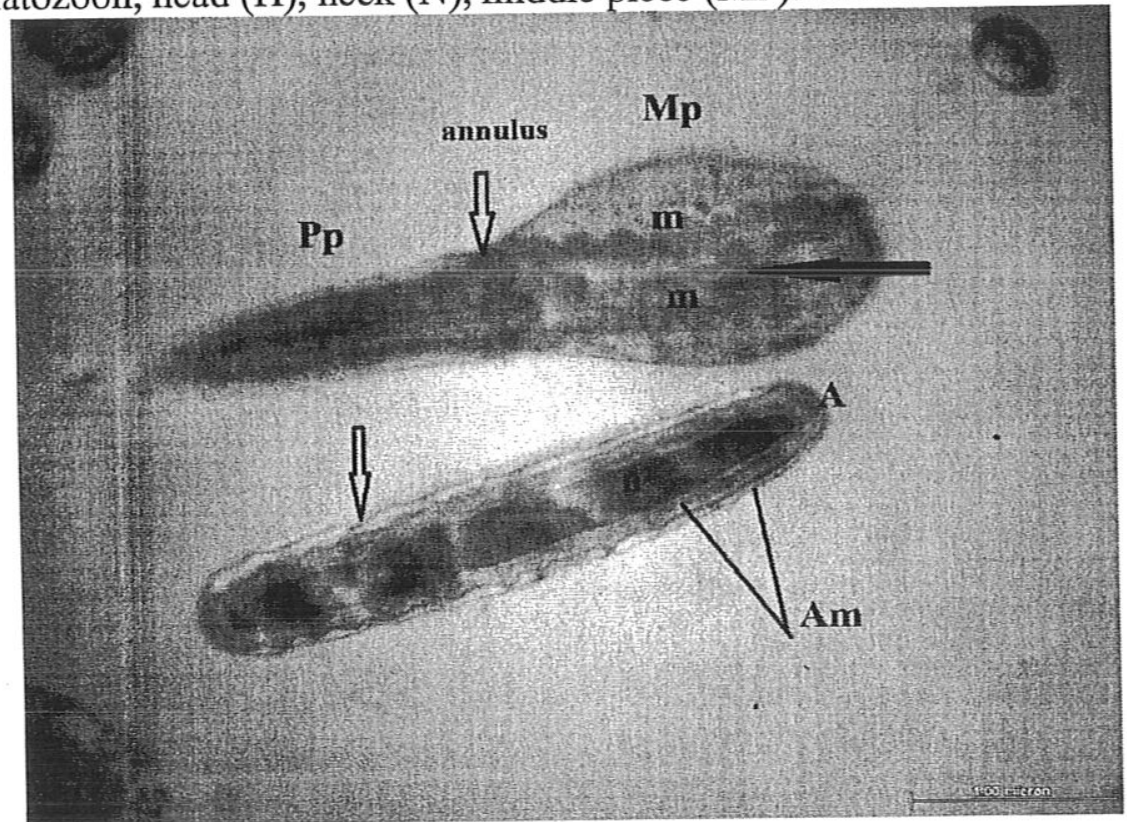

Fig. 2. Electron micrograph of normal semen of adult buffalo bull showing longitudinal section of sperm tail formed from middle piece (Mp) consists of mitochondria (m), axial filament (black arrow), the beginning of the principle piece (Pp) and the (annulus) and also showing longitudinal section of sperm head consists of nucleus (n), plasma membrane (emptyarrow) and the acrosome $(\mathrm{A})$, the acrosome consists of inner and outer acrosomal membrane (AM):X 15000 


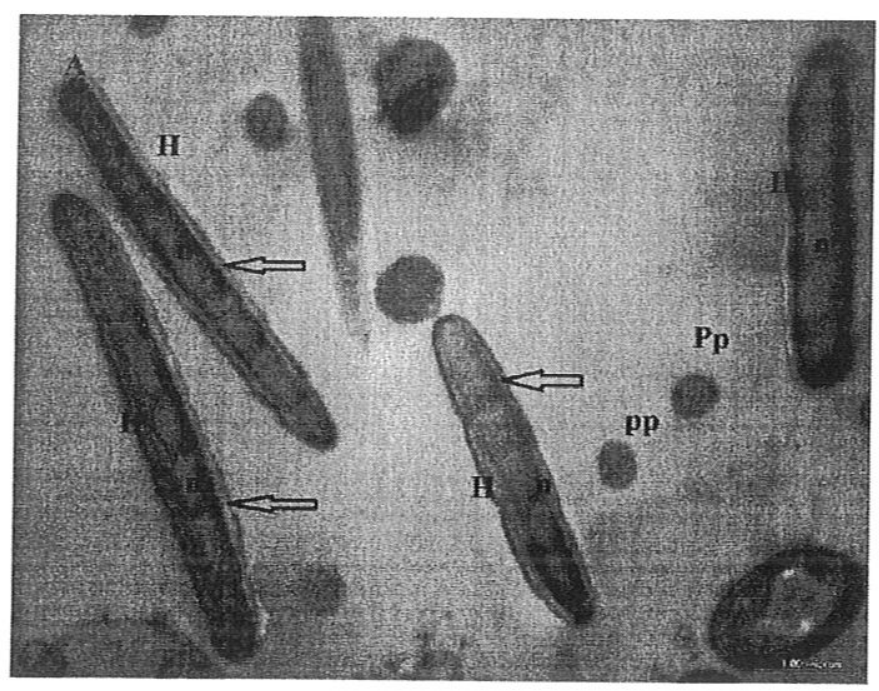

Fig. 3. Electron micrograph of normal semen of adult buffalo bull showing longitudinal sections of many sperm heads $(\mathrm{H})$ formed from nucleus $(\mathrm{n})$, acrosome $(\mathrm{A})$ and plasma membrane (arrows) and C.S of principle pieces (Pp) :X10000

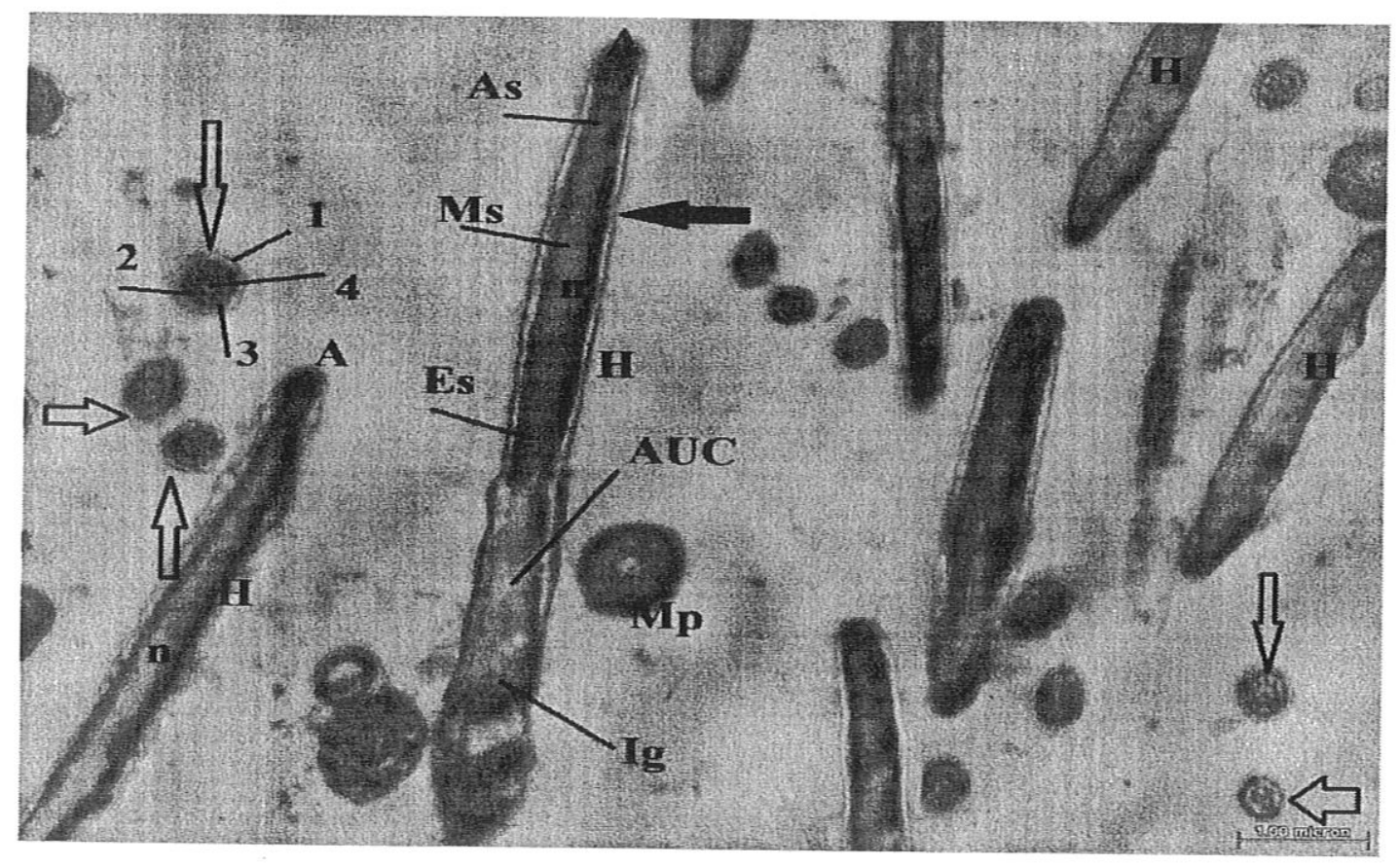

Fig. 4. Electron micrograph of normal semen of adult buffalo bull showing L.S of sperm consists of head (H) formed from nucleus (n), acrosome (A) divided into apical segment (AS) or acrosomal ridge, main segment (MS) and equatorial segment (ES) and plasma membrane ( black arrow), the nucleus (n) ended with implantation groove (Ig) and contain area of uncondensed chromatin (AUC), C.S in middle piece (Mp) and C.S of principle pieces (empty arrows) consists of: 1(cell membrane), 2( longitudinal column), 3(rib of fibrous sheath) and 4( axial filament): X8000 


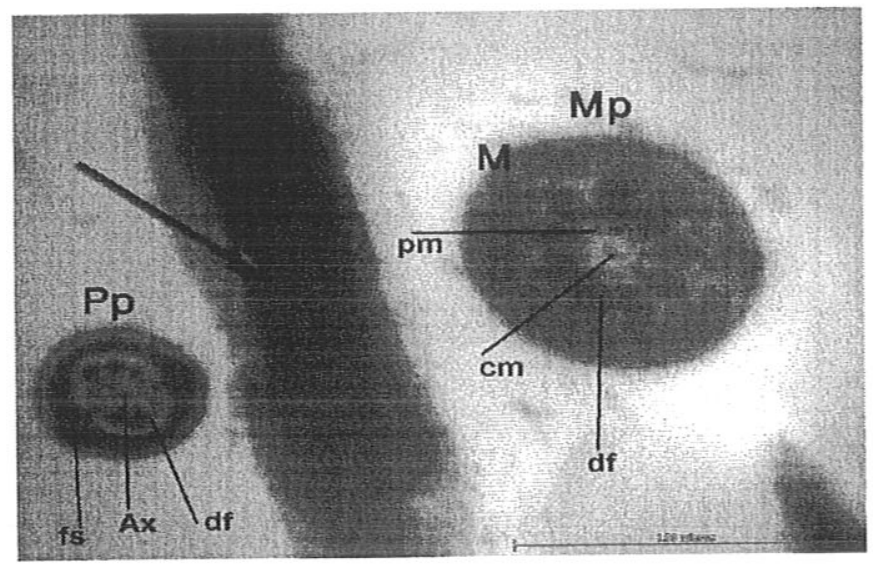

Fig. 5. Electron micrograph of normal semen of adult buffalo bull showing longitudinal section of sperm head (arrow), cross section of middle piece (MP) formed from axoneme $\{$ two central microtubules $(\mathrm{cm})$ and nine peripheral microtubules $(\mathrm{pm})$ and nine dense fibers (df) surrounded by mitochondria (M) $\}$ and cross section of principle piece (Pp) of sperm tail formed from axoneme (Ax), nine dense fibers (df) and fibrous sheath (fs): X 40000

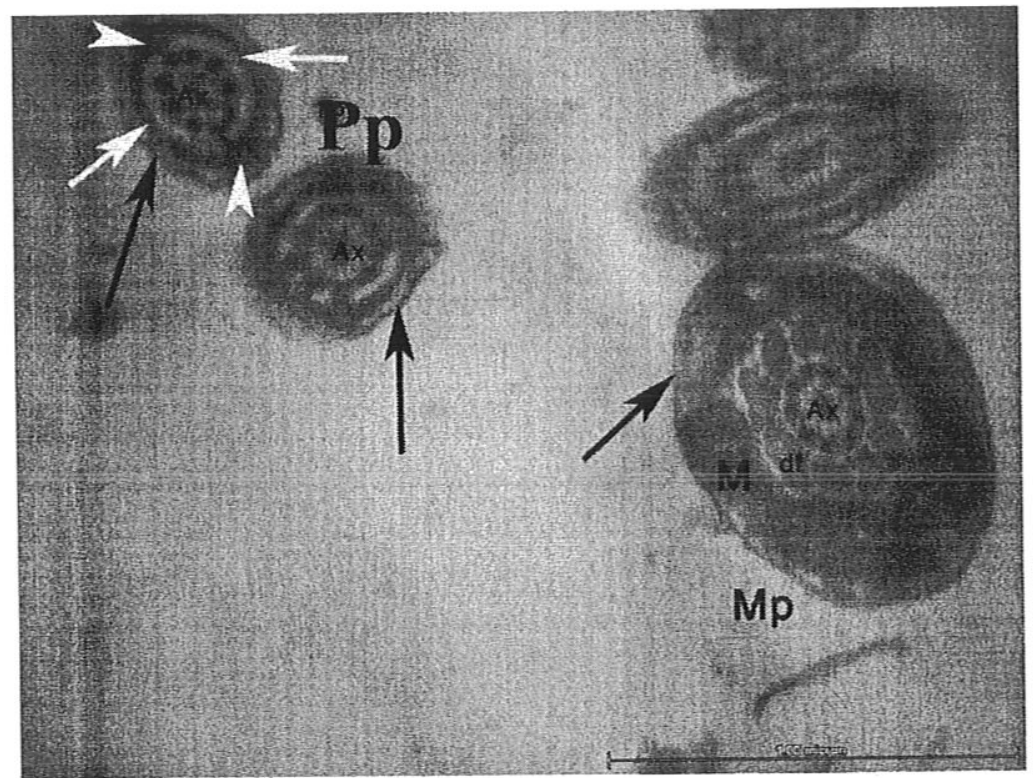

Fig. 6. Electron micrograph of normal semen of adult buffalo bull showing C.S of middle piece (Mp) consists of plasma membrane (black arrow), mitochondria (M), dense fibers (df) and axonem (Ax) and principle pieces (Pp) consists of: plasma membrane (black arrow), longitudinal column (arrow head), rib of fibrous sheath (white arrow) and axoneme (Ax): X40000 


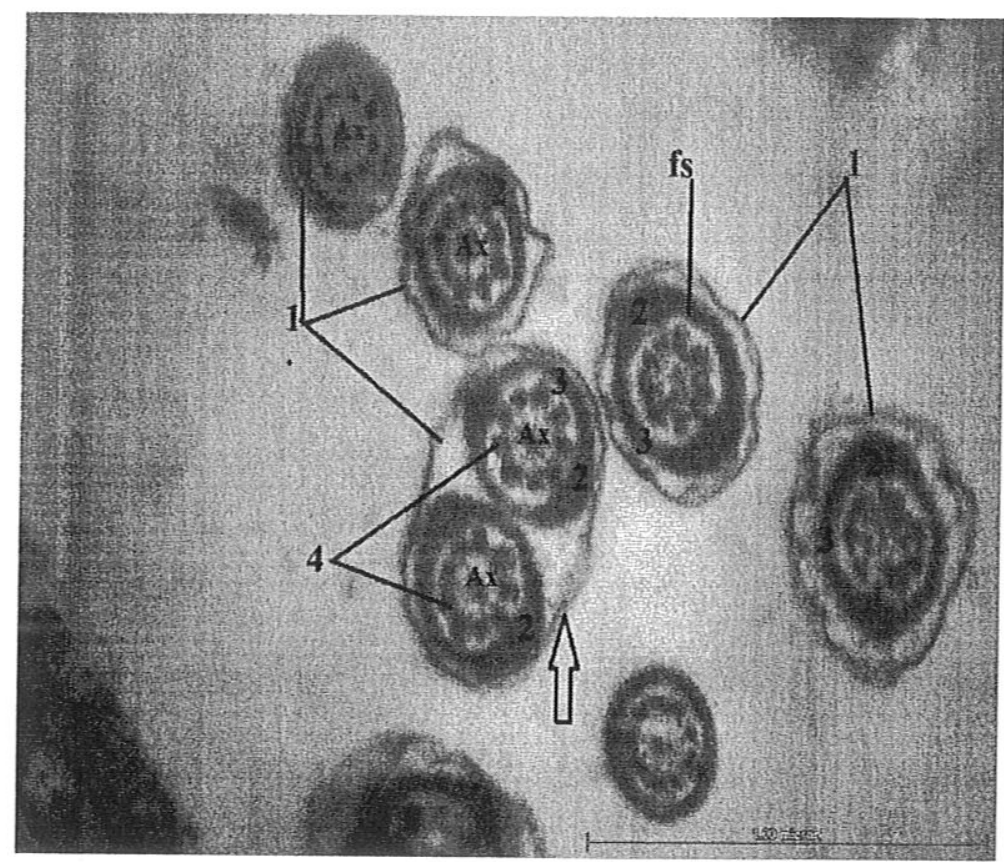

Fig. 7. Electron micrograph of normal semen of adult buffalo bull showing C.S in principle pieces at different levels consists of : 1( cell membrane), fs (fibrous sheath), 2 (longitudinal column), 3 ( rib of fibrous sheath), 4 (dense fibrils), Ax (axial filament) and also showing double tail (empty arrow): X40000

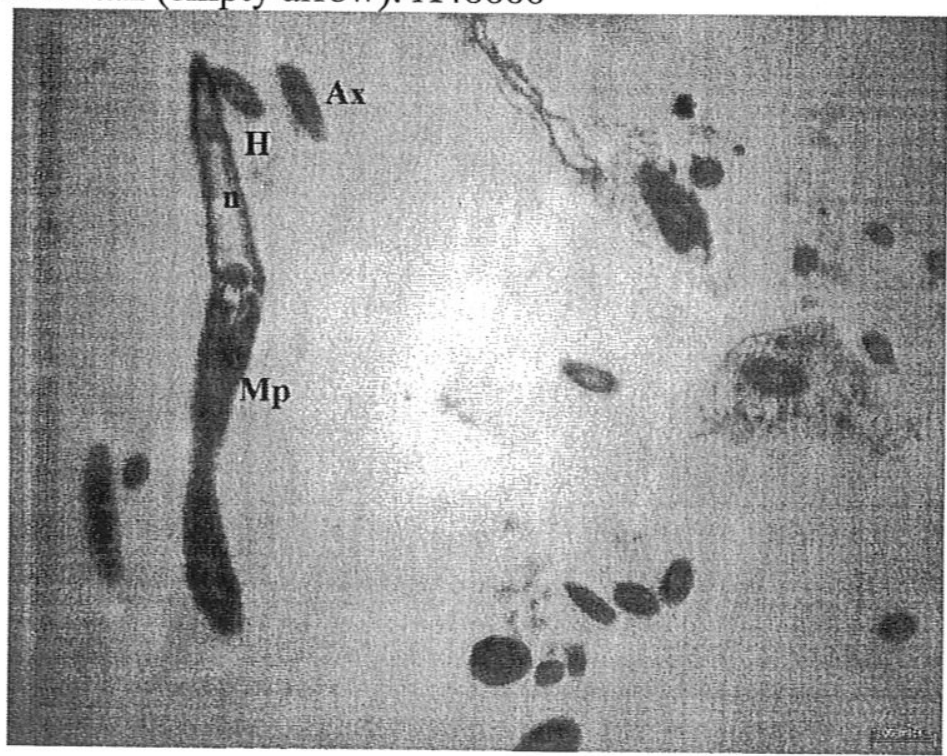

Fig. 8. Electron micrograph of post-thawing semen of adult buffalo bull showing longitudinal section of spermatozoon consists of head $(\mathrm{H})$, middle piece $(\mathrm{Mp})$, this image show short head, absence of plasma membrane, decondensation of chromatin of the nucleus (n), bent constricted middle piece and longitudinal sections of distorded axonemes as a defect of freezing process: X6000 


\section{Fatma et al.,}

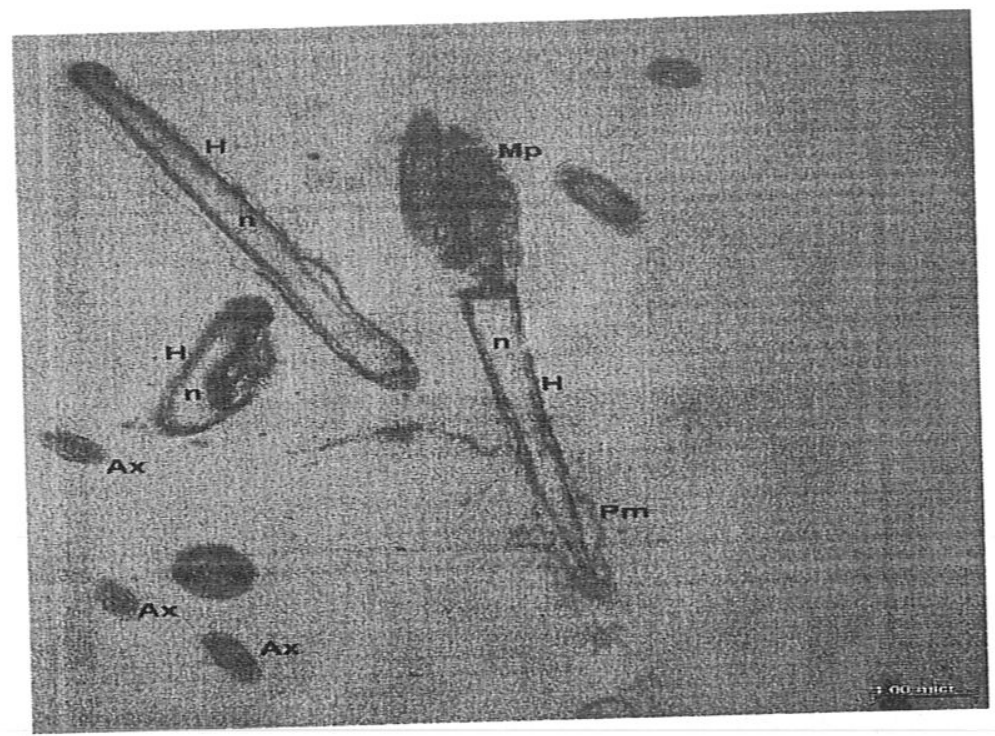

Fig. 9. Electron micrograph of post-thawing semen of adult buffalo bull showing longitudinal section of spermatozoon consist of head $(\mathrm{H})$, middle piece $(\mathrm{Mp})$ and longitudinal section of sperm heads $(\mathrm{H})$. This image shows disrupted plasma membrane $(\mathrm{Pm})$, decondensation of chromatin of the nucleus (n), longitudinal sections of distorded axonemes and disordering of the mitochondria of middle piece as a defect of freezing process: X6000

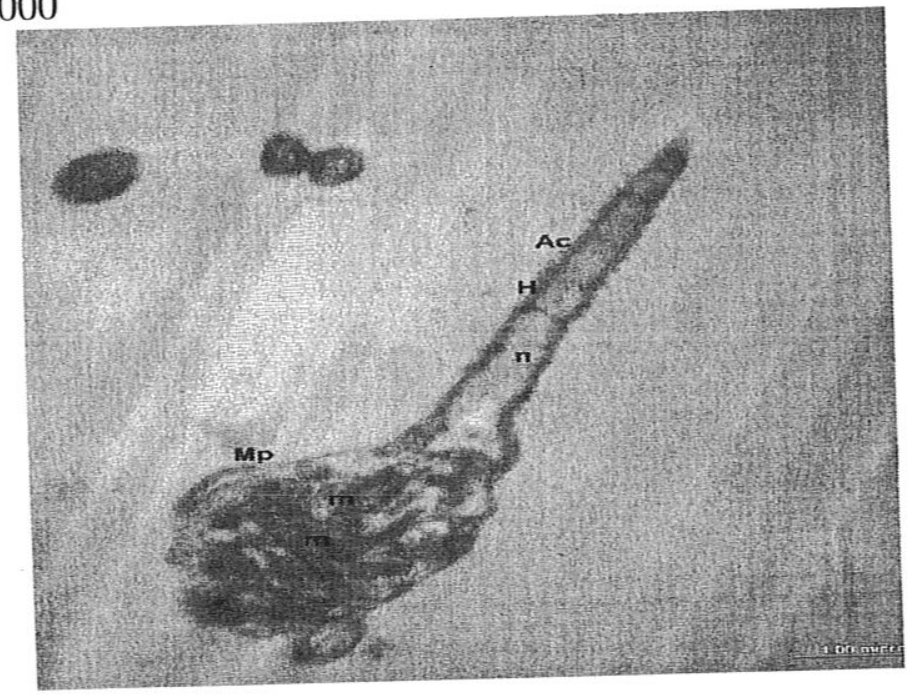

Fig. 10. Electron micrograph of post-thawing semen of adult buffalo bull showing longitudinal section of spermatozoon consists of head $(\mathrm{H})$, middle piece $(\mathrm{Mp})$. This image shows absence of plasma membrane, disintegration of acrosome (Ac) and remnants of its content adhering to the nucleus, decondensation of chromatin of the nucleus (n) and also shows swelling of middle piece and irregular shaped disordered mitochondria $(\mathrm{m})$ as a defect of freezing process: X10000 


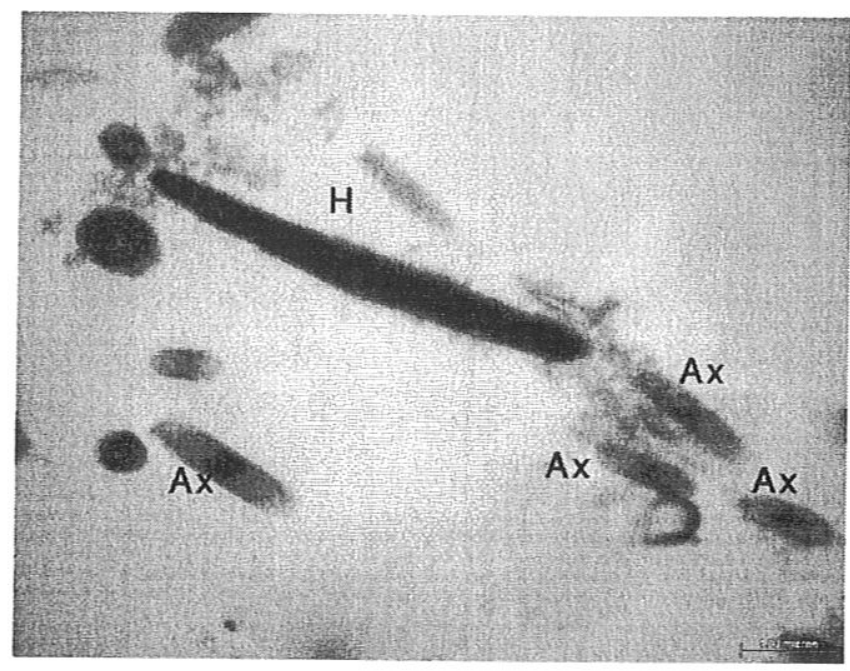

Fig. 11. Electron micrograph of post-thawing semen of adult buffalo bull showing longitudinal section of sperm head (with detached acrosome and destructed plasmalemma as a defect of freezing process) and longitudinal sections of distorded axonemes: X1000

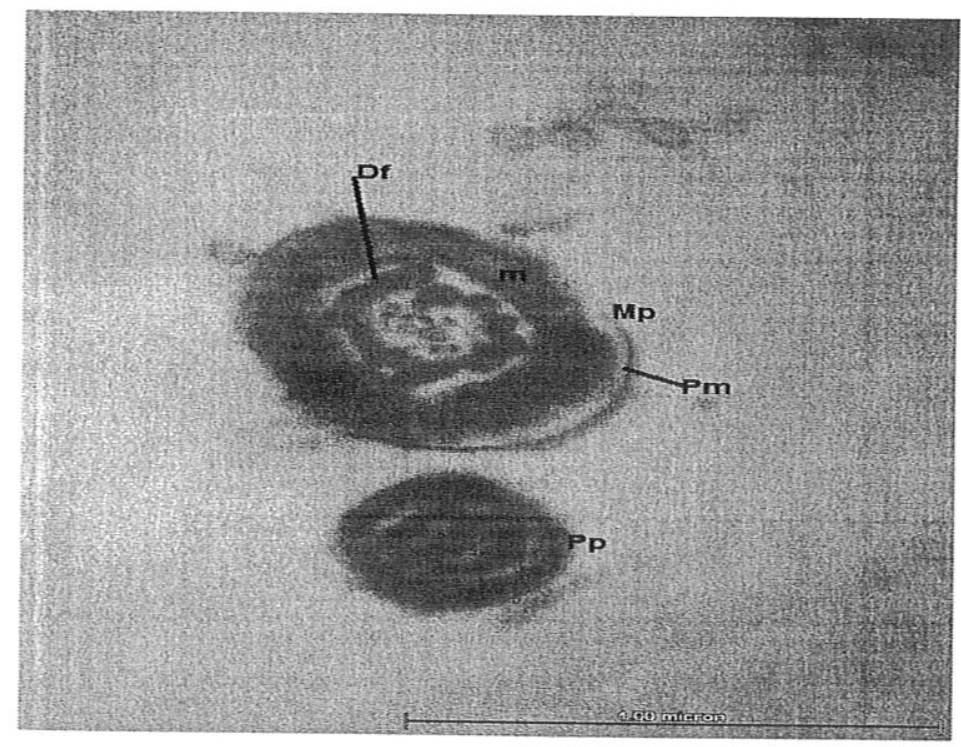

Fig. 12. Electron micrograph of post-thawing semen of adult buffalo bull showing cross section of middle piece $(\mathrm{Mp})$ and principle piece $(\mathrm{Pp})$. This image also shows destructed plasma membrane (Pm) and irregular arrangement and shape of dense fibers (Df) as a defect of freezing process: $\mathrm{X} 30000$ 


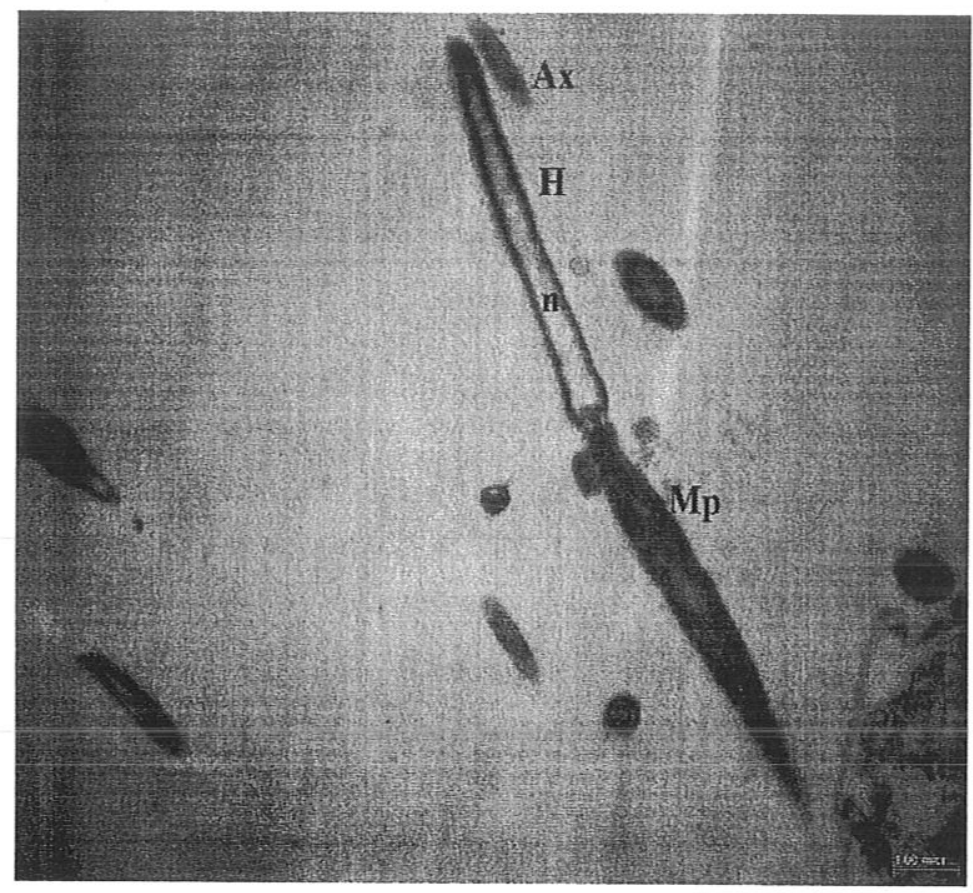

Fig. 13. Electron micrograph of post-thawing semen of adult buffalo bull showing longitudinal section of spermatozoon consists of head $(\mathrm{H})$, middle piece (Mp). This image shows absence of plasma membrane, decondensation of chromatin of the nucleus (n) and longitudinal section of distorded axonemes as a defect of freezing process: X 6000

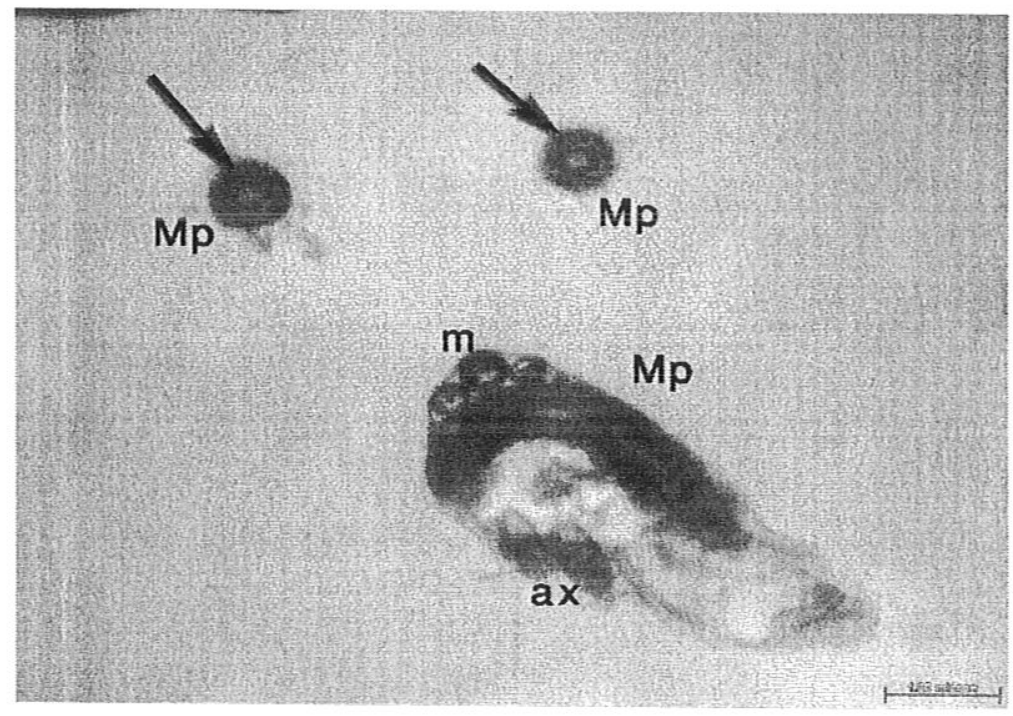

Fig. 14. Electron micrograph of post-thawing semen of adult buffalo bull showing cross section of two middle piece (Mp), the mitochondria of middle piece (arrows) and longitudinal section of middle piece, axoneme (ax), mitochondria (m). This middle piece subjected to benting as a defect of freezing process: X10000 


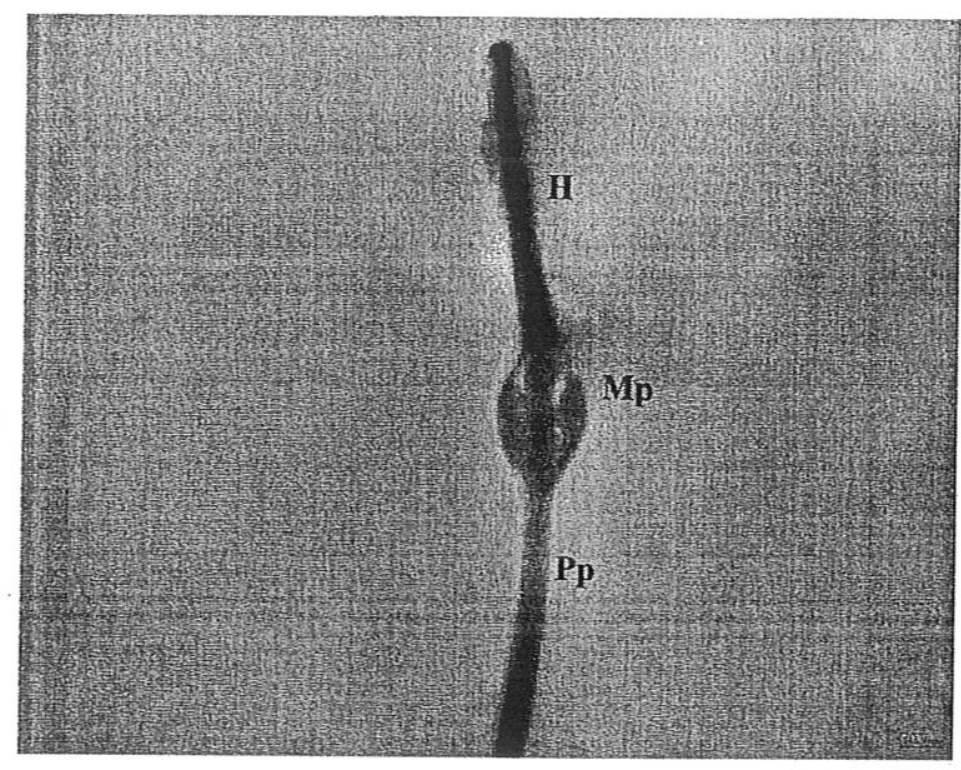

Fig. 15. Electron micrograph of post-thawing semen of adult buffalo bull showing longitudinal section of sperm consists of head $(\mathrm{H})$, swelled middle piece $(\mathrm{Mp})$ and principle piece (Pp).: X4000

\section{DISCUSSION}

The present study showed that, the buffalo bull spermatozoa of freshly collected semen consist of: head and tail (the tail consists of neck, middle piece, principle piece and end piece). These results proved by some authors (13-15). The tail attachment to the head is axial in position. This result was confirmed by other author (16).

Abnormal spermatozoa are detected by staining methods and are usually classified as head, middle-piece and tail abnormalities (17).

The plasma membrane surrounds the spermatozoon in total and is characterized by a regional specific glycoprotein and lipid constitution. These so-called surface domains are important for the function of the membrane areas (18). For example, the part of the membrane at the equatorial segment is responsible for the contact to the oocyte membrane in fertilization (19). Frozen spermatozoa were characterized by disruption and undulation of plasma membrane. These results were parallel to the previous findings of many investigators who observed absence, destruction or damage of the plasma membrane $(20,21)$.

The present study showed that the head consists of acrosome and the nucleus being surrounded by the plasma membrane. The acrosome forms a cap-like structure covering the first two thirds of the sperm head. It consists of the inner and outer acrosomal membranes and it is cut into three different segments; (a) the anterior margin (b) the main segmentand (c) the equatorial segment. These results proved by some authors (14).The equatorial segment is responsible for the contact to the oocyte membrane in fertilization (19).

The effect of cryopreservation on acrosome of frozen spermatozoa represented in detached acrosome. This was in agreement with many authors (21). Rupture of both the outer acrosomal membrane as well as the plasma membrane covering the acrosome may occur. This was similar to the observations of some authors $(20,22)$. The disintegration of acrosome and remnants of its content adhering to the nucleus was also described by other author (22). 
The nucleus contains the condensed chromatin. In buffalo, the shape of the nucleus is species-specific and usually flattened dorsoventrally; the outline tends to be oval. This finding was similar to the statement of some authors (14). In transmission electron microscopy, it appears to be very dense because the chromatin is highly condensed and it is arranged lamella-like due to exchange of histones to protamines $(19,23)$. Only in the neck region, there is a small area of uncondensed chromatin where transcription, translation and protein-biosynthesis are still possible $(24,25)$.

The nuclear membrane and the inner acrosomal membrane form the nuclear envelope (14). On the other hand, this study showed that the frozen buffalo bull spermatozoa characterized by decondensation of chromatin of the nucleus because of denaturation of deoxyribonucleic acid (DNA) due to freezing process and this affects on fertilization process. These results were obtained by many authors (21). There is now a substantial body of evidence to support the conclusion that the integrity of sperm chromatin is important not only for fertilization but also normal embryonic development $(26,27)$.

The present work showed that the neck is a relatively short and narrow strucrure between the head and middle piece (connecting piece) (13). In this study, the midpiece is characterized by the mitochondrial sheath that surrounds the axonemal complex and the nine ODF. The ODF and fibrous sheaths are two unique cytoskeletal elements along the central axoneme which distinguish the tail from simple flagella or cilia (28-30).

The present work revealed that the mitochondria are arranged end to end in helices around the contractile elements for high flexibility as reported by some authors (14). It wraps laterally around the outer dense fiber in cross section (16). The mitochondria might be to provide adenosine triphosphate (ATP) for sperm movement through oxidative phosphorylation so; defects of mitochondria hinder the metabolic activity and consequently movement of sperm (7).
Frozen buffalo bull spermatozoa characterized by bent middle piece. These results were confirmed by many authors (21, 31) who cited that swelling of middle piece due to change in osmotic pressure. Breakage of the plasma membrane of middle piece and loss of some of the mitochondria (20), irregular shaped mitochondria (32) and disordered mitochondria (mitochondria is out of its normal position) (33). All these changes may be resulted as sequelae of freezing process.

In this study, the results showed that the principle piece is the longest portion of the spermatozoon. The axial filament complex has a structure identical to that of middle piece and is surrounded by the continuing outer fibers of the middle piece. These results proved by some authors (13). One row of radial spokes radiate inward toward the central pair of microtubules. Similar results were obtained by many authors (14).

The principle piece is enclosed by fibrous sheaths that are made of two longitudinal columns, a dorsal and a ventral one, and circumferentially oriented connecting ribs (34, 35). The fibrous sheaths work as a scaffold for proteins in signalling pathways, so it might be involved in regulation of sperm maturation, motility, capacitation and hyper activation (35).

In this study principle piece was found with different sizes in cross section so we divide the principle piece into two level (a) level 1 at the upper third of principle piece and (b) level 2 at the lower third of principle piece because the thickness of the principle piece decreases toward the end piece, While frozen buffalo bull spermatozoa characterized by irregular arrangement and shape of dense fiber. This was also reported by some authors (32)and distorded axonemes as effect of freezing and this affected movement of spermatozoa (36). This result was not similar to other studied (37). The dense fibers facilitate sperm movement which required for the penetration of oocyte and serve as protector against damage during sperm transition through the female reproductive tract so defects of these fibers may affect the fertilization process (38). 
The damage to sperm through freezing processes and after thawing have been attributed to several factors including cold shock, freezing injury, oxidative stress, alterations in membrane compositions, chemical toxicity of cryoprotective agents (CPA), and osmotic stress (39). Cryopreservation induces many changes in sperm cells, including membrane disorders and cell death. The apoptosis, a form of programmed cell death, can contribute to the fatal effect of cryopreservation on sperm cells (40).

Finally, the problem about semen cryopreservation is that arrest in the metabolic processes within the spermatozoa is required. So, the cells need to be held in a state of "suspended animation" until required for fertilization. Series of osmotic, chemical and mechanical stress are induced by cryopreservation so; freezing-protocols should be well puzzled out to minimize these stresses.

\section{REFERENCES}

1.FAO (2004):Live stock census cited: http:/www.fao.org.

2.Vishwanath $R$ and Shannon $P$ (2000): Storage of bovine semen in liquid and frozen state. Anim.Reprod. Sci., 62(1-3):23.

3.Holt (2000): Fundamental aspects of sperm cryobiology: The importance of species and individual differences. Theriogenology.60: 743-758

4.Benson J D, Woods $E$, Walters $E M$, Crister $J K$ (2012): The Cryobiology of Spermatozoa. Theriogenology. 78: 16821699.

5.Gravance CG, Vishwanath R, Pitt C, Garner $D L$ and Casey $P J$ (1998):Effect of cryopreservation on bull sperm head morphometry. Journal of Andrology, Vol / 9.No. 6.

6.Rochwerger L, Cuaniscu PS (1992): Redistribution of a rat sperm epydidimal glycoprotein after "in vitro" and "in vivo" capacitation. Mol. Reprod. Dev. 31, 34-40.

7.Santos J R, Amaral A, Sousa A P, Rodrigues AS, Martins L, Baptista M, Mota PC, Tavares $R$, Amaral $S$ and Gamboa $S$ (2007):Probing the Structure and Function of Mammalian Sperm using Optical and Fluorescence Microscopy, Journal of andrology. vol.17 No.6.

8.Menon A G, Barkema HW and Thundathil JC (2011): Associations between sperm abnormalities, breed, age, and scrotal circumference in beef bulls .Can. J. Vet. Res. 75(4):241-247.

9.Zemjanis $R$ (1970): Diagnostic and therapeutic techniques in animal reproduction. Sec.,Balliere Tindal and Cox Ltd., London.

10.Hayat $M A$ (1986):Basic techniques for transmission electron microscope, Academic press, Jovnovich publishers. Inc. Harcourt Brace, New York.

11.Coffin DL (1953):Manual of veterinary clinical pathology $\cdot 3^{\text {rd }}$ Ed. Comstock Pub1. Co., Ithaca, N. Y.

12. Salisbury $G W$, Beck $G H$, Elliot $J$ and Willett $E$ L (1943): Rapid method of estimating the number of spermatozoa in bull semen .J. Dairy Sci., 38:1.

13.Dellmann DH and Eurell AJ (1998):Male reproductive system in text book of veterinary histology. William and Wilkins. Waverly company Baltimore, Maryland.

14.Pesch $S$ and Bergmann $M$ (2006):Structure of mammalian spermatozoa in respect to viability, fertility and cryopreservation .micron, 37, 597:612.

15Jeong S, Park J, Kim H, Bae CS, Yoon M, Lim $D$ and Jeong, $M$ (2006):Comparative fine structure of the epididymal spermatozoa from three korean shrews with 
considerations on their phylogenetic relationships. Biocell., 30(2): 279-286.

16.Heath E, Mustafa MS and Karasek $S$ (1986): Ultrastructure of camel (camelus dromedaries) spermatozoa. Anat. Histol. Embryol., 15,147-154.

17.Kumar S, Sahni K L, Bistha G S (1993): Cytomorphological characteristics of motile and static semen of buffalo bulls. Buffalo J. 2, 117-127.

18.Topfer $P$ and Waberski (2001):Sperm maturation and fertilization. In: Busch, W., Holzmann, A. (Eds.), Veterinary Medicine Andrology, Physiology, Pathology of Reproduction in Male Animals. Schattauer, Stuttgart, pp. 69-72.

19.Rovan $E$ (2001): Biochemistry of spermatozoa. In: Busch, W., Holzmann, A. (Eds.), Veterinary Medicine Andrology, Physiology and Pathology of Reproduction in Male Animals.Schattauer, Stuttgart, pp. 23-54.

20.Jones $R C$ and Stewart $D L$ (1979): The effects of cooling to $5 \backslash \mathrm{s}=\mathrm{deg} \backslash$ Cand freezing and thawing On the ultrastructure of bull spermatozoa J.Reprod.Fert., 56:233- 238.

21.Sinan O, Esra E, Ayca I, Derya, $O$ and Sercin $K$ (2008):Effects of cryopreservation on sperm parameters and ultrastructural morphology of human spermatozoa. J. Assist. Reprod. Genet., 25 (8): 403-411.

22.Healey $P$ (1969): Effect of freezing on ultrastructure of spermatozoon of some domestic animals.J. Reprod. Fert.,18:21-27.

23.Steger $K \quad$ (1999):Transcriptional and translational regulation of gene expression in haploid spermatids. Anat. Embryol., (Berlin) 199, 471-487.

24.Dadoune $J P$, Siffroi $J P$, Alfonsi $M F$, (2004):Transcription in haploid malegerm cells. Int. Rev. Cytol. 237, 1-56.

25.Miller D, Ostermeier $G C$ and Krawetz $S A$ (2005):The controversy, potential and roles of spermatozoal RNA. Trends Mol. Med., 11: $156-163$.
26.Ward W S, Kishikawa H, Akutsu H, Yanagimachi H, Yanagimachi $R$ (2000): Further evidence that sperm nuclear proteins are necessary for embryogenesis. Zygote 8, 51-56.

27.Morris I D, Ilott $S$, Dixon $L$, Brison $D R$ (2002): The spectrum of DNA damage in human sperm assessed by singlecell gel electrophoresis (Comet assay) and its relationship to fertilisation and embryo development. Hum. Reprod. 17, 990-998.

\section{Olson $G E$, Hamilton $D W$ and Fawcett $D$} $W$ (1976):Isolation and characterization of the fibrous sheath of the rat epididymal spermatozoa. Biol. Reprod.,14, 517-530.

29.Irons $M J$ and Clermont $Y$ (1982): Formation of the outer dense fibers during spermiogenesis in the rat. Anatom.Rec., 202, 463-471, J. Repro.Fert., 18, 21-27.

30.Oko $R$ and Clermont $Y$ (1989):Light microscopic immunocytochemical study of fibrous sheath and outer dense fiber formation in the rat spermatid. Anatom. Rec., 225:46-55.

31.Bakst $M R$ and Sexton $T J$ (1979): Fertilizing capacity and ultrastructure of fowel and turkey spermatozoa before and after freezing. J. Reprod. Fert., 55:1-7.

32.Hashida, $N$ H, Abdullah $R$ B, Rajikin M H and Mat Noor M (2005):Ultrastructural studies of fresh, frozen-thawed and acrosome- reacted goat sperm Biomedical Research 2005; $16 \quad$ (2): 119 123international Journal of dairy technology ,54 (2):41.

\section{Espinoza $C$, Valdivia $M$ and Dupré $E$} (2010): Morphological alterations in cryopreserved spermatozoa of scallop Argopectenpurpuratus (Lat. Am. J. Aquat. Res., 38(1): 121-128, 20M10o Morphology of cryopreserved sperm Argopectenpurpuratus121.

34.Fawcett $D W$ (1961):Sperm tail structure in relation to the mechanism of movement. In: Bishop, D. (Ed.), Spermatozoon Motility. A.A.A.S., Washington, pp. 147-169. 
35.Eddy $E$ M, Toshimori $K$ and O'Brien D A (2003): Fibrous sheath of mammalian spermatozoa. Microsc. Res. Tech., 61, 103115.

36. Nath J (1972): Correlative biochemical and ultrastructural studies on the mechanism of freezing damage to ram semen. Cryobiology; 9: 240-246.

37. Zibrin M Belák M, Mesároš P, GamčíkP, Tomajková E(1987):The ultrastructure of frozen-thawed ram spermatozoa. Z Mikrosk. Anat. Forsch; 101: 904-912.
38. Tash $J S$ and Means A $R$ (1983):Cyclic adenosine 3,5 monophosphate, calcium and protein phosphorylation in flagellar motility. Biol.Reprod. 28:75-104.

39.Critser $J K$ and Mobraaten $L E$ (2000): Cryopreservation of rats spermatozoa. ILAR J., 41:197, Cryobiology 64 (2012) 103-109.

40. Martin G, Sabido $O$, Durand $P$ and Levy $R$ (2004): Cryopreservation Induces an Apoptosis-Like Mechanism in Bull Sperm. Biology of Reproduction. 71(1): 28-37.

\section{الملخص العربي}

الار اسات الشكلية في مراحل الحفظ بالتجميد للحيوانات المنوية لطلائق الجــاموس

فاطمة محمد علي ابراهيم، حسن على حلمى منصور، فاتن محمد لبيب، حسين أحمد عامر، رشار رجب

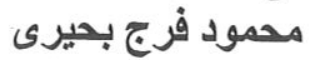

قسم التوليد و النتاسل و التلقيح الاصطناعى وقسم الانسجة و الخلايا- كلية الطب البيطرى- جامعة الزقازيث

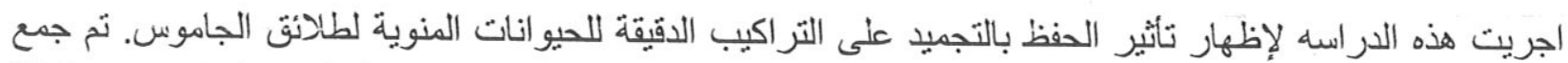

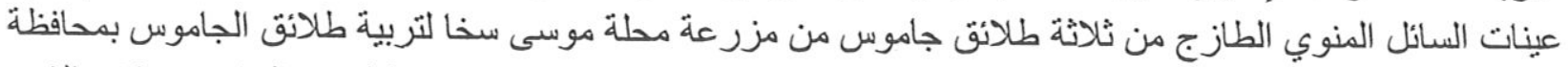

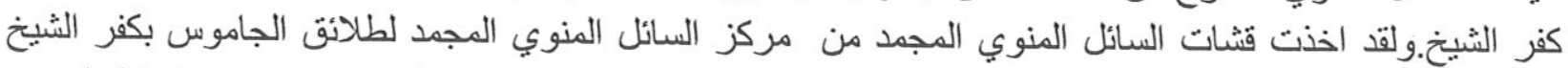

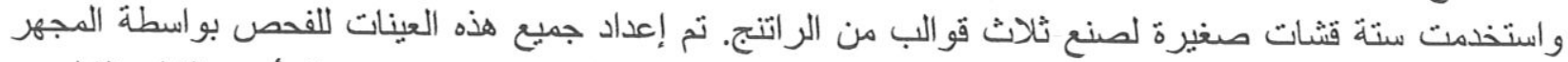

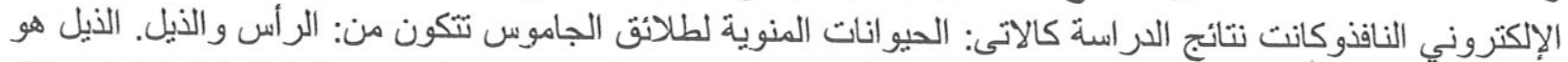

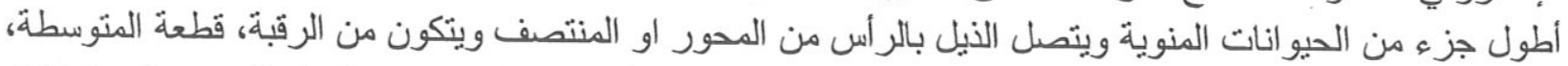

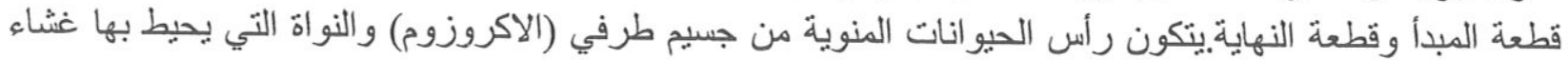

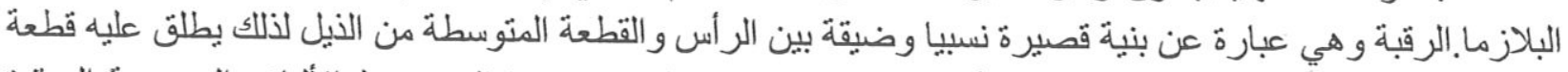

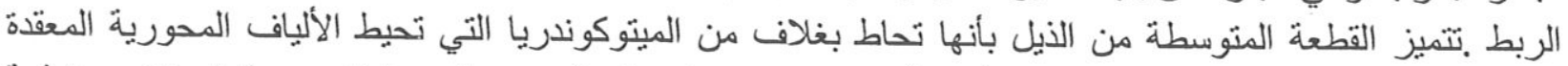

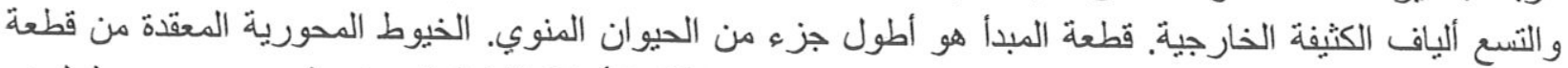

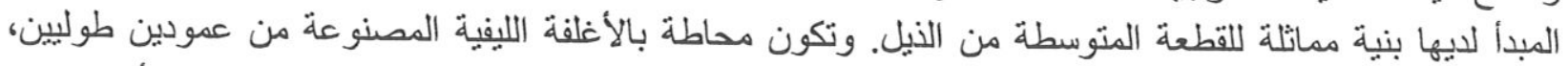
(أحدهم ظهري و الأخر بطني). قطعة النهاية تحتوي فقط على الخيوط المعقدة المحورية. وكشفت النتائج أبضا نتائج

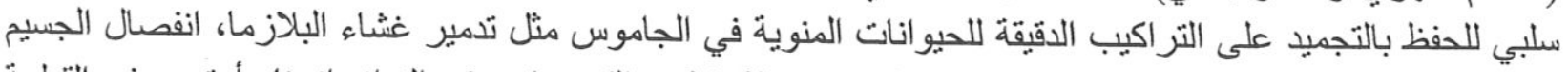

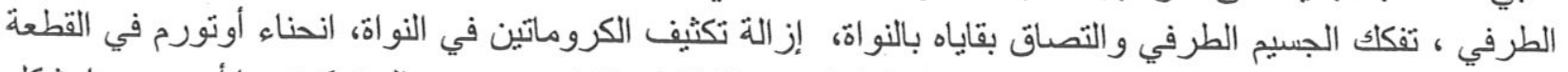

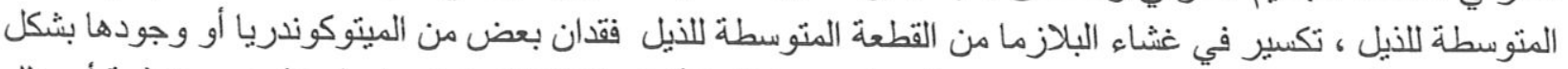

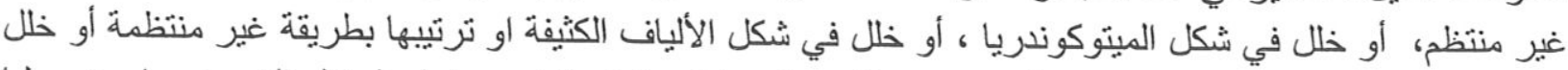

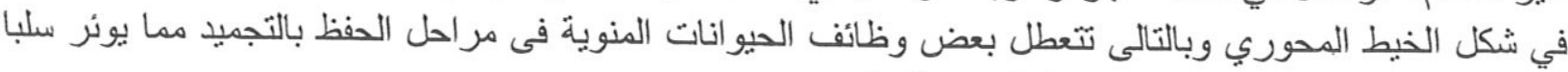

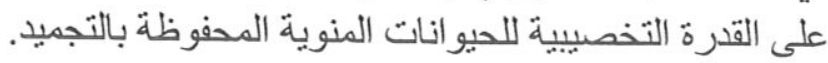

